\title{
Outcome of Emergency Surgery in HIV Infected Patients in Jos
}

\author{
Isichei M.W. FWACS ${ }^{1}$, Misauno M.A. FWACS ${ }^{1}$, Shitta A.H FWACS ${ }^{1}$,Isichei \\ C.O Fmcpath ${ }^{2}$ \\ ${ }^{1}$ (Department of Surgery of the Jos University Teaching Hospital) \\ ${ }^{2}$ (Department of Chemical Pathology, Jos University Teaching Hospital)
}

\begin{abstract}
Surgery in the immune compromised such as the HIV infected patients is a subject shrouded with some doubt and controversy because of the complications that are thought to arise following the surgery. The surgeries performed during the study period were not minimally invasive or highly specialized and was performed by general practitioners, general surgeons and gynecologist. We evaluated the outcomes of emergency surgeries among our patients using the CD4 cell count and the Hemoglobin concentration as predictors of outcome in HIV patients undergoing surgery in our clinic. This was a combined retrospective and prospective evaluation of HIV positive patients who underwent surgery at a Nongovernmental medical facility that renders free care to H IV positive patients in Jos Plateau State from January 2011- December 2013.All consenting patient and those with available medical records were recruited into the study. Non consenting patients, those with missing records and those lost to follow up were excluded from this study. Data was extracted on the type of surgery, duration of hospital stay, and complications was analyzed then matched with the hematological and immunological parameters of the patients. Obtained data was obtained using epi info version 7. Analysis was for means and standard. A total of 282 major surgeries were performed. $102(36.17 \%)$ of the patients had Obstetrics and Gynaecological surgeries, 68(24.11\%0 had appendectomies, 26(9.22\%) had exploratory Laparotomies, 23(8.16\%0 Urologic, Orthopedic surgeries accounted for 13(4.61\%); wile Pediatric surgeries accounted for 11(3.90\%), other minor procedures accounted for 39(13.83\%). The study population had a mean CD4 count 168.8 $.140 .5 \mathrm{cell} / \mathrm{ml}$ and a mean Hemoglobin concentration of $12.3^{+} .4 .9 \mathrm{grms}$. One hundred and ten patients (39\%) healed normally and were discharged without complications, wile 114(40.3\%) ad delayed wound healing and were discharged home after two weeks. There was $20.7 \%$ mortality in this study (58 patients).Patients that ad delayed wound healing had a mean CD4 count of 160, while mortality was seen in patients with a mean CD4 count of 150. Emergency surgery in IV infected patients with a low CD4 cell count is associated with a high morbidity and mortality.
\end{abstract}

Keywords: Outcome, emergency, surgery, HIV infected

\section{Introduction}

Surgery in the immune compromised such as the HIV infected patients is a subject shrouded with some doubt and controversy because of the complications that are thought to arise following the surgery(1). A surgeon would want to optimize the hematological, immunological and the biochemical indices before performing surgery on the HIV infected patient (2-3). The indices for good outcome include Hemoglobin concentration of $>10$ gram, CD4 cell of $>500$ cells $/ \mathrm{ml}$, good liver and renal functions in a patient who is stable on Antiretroviral drugs(4). For patients going for elective surgery with no impending complication, one has the luxury of waiting till the desired indices are obtained in the patients (5-6),. In emergency situations the surgeon has to weigh the risk of operating versus not operating until the optimal parameters are reached (7). The decision is often a difficult one but where delay may put the patient in greater danger, the surgeon may consider operating on the patient. The outcome in elective case has been found to be better compared to the emergency cases(8).

Surgeons have implored various means of improving the outcome in those going for emergency; such measures include blood transfusion, judicious use of broad spectrum antibiotics, parenteral nutrition, injectable antiretroviral drugs, minimally invasive surgeries, highly specialized surgeries and short operating time(9). In low and middle income countries such as ours, minimally invasive and highly specialized surgeries, parenteral nutrition and injectable antiretroviral are not readily available. Were it is available are not affordable for the majority of the population. Despite the constraints surgeries are performed on the HIV infected patients for both elective and emergence cases. Our determinants for fitness to be operated upon are mainly based on the hematological, immunological and the biochemical indices.The surgeries performed during the study period were not minimally invasive or highly specialized and was performed by general practitioners, general surgeons and gynecologist. We evaluated the outcomes of emergency surgeries among our patients using the CD4 cell count and the Hemoglobin concentration as predictors of outcome in HIV patients undergoing surgery in our clinic. 


\section{Patients And Methods}

This was a combined retrospective and prospective evaluation of HIV positive patients who underwent surgery at a Nongovernmental medical facility that renders free care to H IV positive patients in Jos Plateau State from January 2011- December 2013. All consenting patient and those with available medical records were recruited into the study. Non consenting patients, those with missing records and those lost to follow up were excluded from this study.

Data was extracted on the type of surgery, duration of hospital stay, and complications was analyzed then matched with the hematological and immunological parameters of the patients.

Obtained data was obtained using epi info version 7. Analysis was for means and standard

\section{Results}

A total of 282 major surgeries were performed. 102(36.17\%) of te patients had Obstetrics and Gynaecological surgeries, $68(24.11 \% 0$ had appendectomies, $26(9.22 \%)$ had exploratory laparotomies, 23(8.16\%0 Urologic, Orthopedic surgeries accounted for 13(4.61\%); wile Pediatric surgeries accounted for $11(3.90 \%)$, other minor procedures accounted for $39(13.83 \%)$. See fig 1

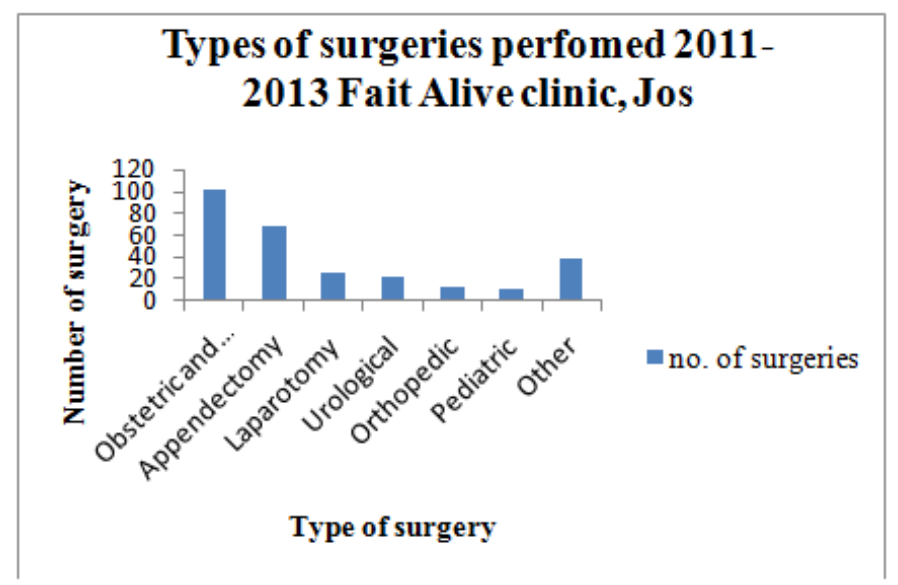

Fig. 1 showing types of emergency surgeries performed

The study population had a mean CD4 count $168.8^{+}$. $140.5 \mathrm{cell} / \mathrm{ml}$ and a mean Hemoglobin concentration of $12.3^{+} .4 .9 \mathrm{grms}$. One hundred and ten patients $(39 \%)$ healed normally and were discharged without complications, wile 114(40.3\%) ad delayed wound healing and were discharged home after two weeks. There was $20.7 \%$ mortality in this study (58 patients). Patients tat ad delayed wound healing had a mean CD4 count of 160 , while mortality was seen in patients with a mean CD4 count of 150 .

\section{Discussion}

The main finding in this study is that low CD4 counts are associated with high morbidity and mortality. Clinical AIDS is state of depressed immunity from a low CD4 count and is generally associated with poor wound healing. Zhang $\mathrm{L}$ et al reported similar findings among HIV patients who had major abdominal surgeries (10-11). Delayed healing was found in patients with a mean CD4 count of $160 \mathrm{cell} / \mathrm{ml}$ wile a high mortality was seen in patients with CD4 counts of 150 cells $/ \mathrm{ml}$ and below. Su, J et al, found that major surgery and a low CD4 cell count positively correlated with high rate of post operative infection, sepsis and a delayed healing (1213). This finding can be explained by the fact that HIV infected patients requiring emergency surgery are likely to be moribund, have poor nutritional status in addition to the low CD4 cell count, low Hemoglobin concentration and are of poor anesthetic risk making them candidates for increased morbidity and mortality(14-15) . To reduce this high morbidity and mortality associated with emergency surgery in the AIDS patients with a low CD4 count, administration of broad spectrum antibiotics, and correction of fluid and electrolyte derangement, appropriate blood transfusions and use of supplemental parenteral nutrition is advocated.

\section{Conclusion}

Emergency surgery in IV infected patients with a low CD4 cell count is associated with a high morbidity and mortality. 


\section{References}

[1]. Becker K, Erckenbrecht JF. [Preoperative risk assessment and perioperative management of HIV-infected patients]. Med Klin (Munich). 2001 Jan 15;96(1):26-31.

[2]. Bluvshtein GA, Kulakov AA. [Clinical features of surgical diseases at the patients with HIV/AIDS]. Khirurgiia (Mosk). 2007(5):515 .

[3]. Songu M, Portmann D. Otologic surgery in HIV-infected patients. Rev Laryngol Otol Rhinol (Bord). 2008;129(1):61-3.

[4]. Huang WC, Kwon EO, Scardino PT, Eastham JA. Radical prostatectomy in patients infected with human immunodeficiency virus. BJU Int. 2006 Aug;98(2):303-7.

[5]. Smirnov GG, Buliskeriia TN, Khachatrian NN, Volodina VN, Arutiunian EN, Lazutkina LI. [Surgical interventions in HIV-infected and patients with AIDS]. Khirurgiia (Mosk). 2000(7):46-50.

[6]. Nelson L, Fried M, Stewart K. HIV-infected patients: the risks of surgery. J Perioper Pract. 2009 Jan;19(1):24-30.

[7]. Madiba TE, Muckart DJ, Thomson SR. Human immunodeficiency disease: how should it affect surgical decision making? World J Surg. 2009 May;33(5):899-909.

[8]. Karpelowsky J, Millar AJ. Surgical implications of human immunodeficiency virus infections. Semin Pediatr Surg. 2012 May;21(2):125-35

[9]. Muchuweti D, Jonsson KU. Abdominal surgical site infections: a prospective study of determinant factors in Harare, Zimbabwe. Int Wound J. 2013 Sep 19

[10]. Zhang L, Liu BC, Zhang XY, Li L, Xia XJ, Guo RZ. Prevention and treatment of surgical site infection in HIV-infected patients. BMC Infect Dis. 2012;12:115.

[11]. Foschi D, Cellerino P, Corsi F, Casali A, Rizzi A, Righi I, et al. Impact of highly active antiretroviral therapy on outcome of cholecystectomy in patients with human immunodeficiency virus infection. Br J Surg. 2006 Nov;93(11):1383-9.

[12]. Su J, Tsun A, Zhang L, Xia X, Li B, Guo R, et al. Preoperative risk factors influencing the incidence of postoperative sepsis in human immunodeficiency virus-infected patients: a retrospective cohort study. World J Surg. 2013 Apr;37(4):774-9.

[13]. Kigera JW, Straetemans M, Vuhaka SK, Nagel IM, Naddumba EK, Boer K. Is there an increased risk of post-operative surgical site infection after orthopaedic surgery in HIV patients? A systematic review and meta-analysis. PLoS One. 2012;7(8):e42254.

[14]. Jones S, Schechter CB, Smith C, Rose DN. Is HIV infection a risk factor for complications of surgery? Mt Sinai J Med. 2002 Oct;69(5):329-33.

[15]. Wittmann MM, Wittmann A, Wittmann DH. AIDS, emergency operations, and infection control. Infect Control Hosp Epidemiol. 1996 Aug;17(8):532-8. 